\title{
PRAKTIK METODE PENGINJILAN PADA MATA KULIAH METODE PENGINJILAN STT SIMPSON UNGARAN
}

\author{
Jamin Tanhidy \\ Sekolah Tinggi Teologi Simpson Ungaran \\ Jl. Agung No. 66 Krajan, Kel. Susukan, Kec. Ungaran Timur, Kab. Semarang \\ Email: jamin92@gmail.com
}

\begin{abstract}
Jamin Tanhidy, A Practise of Evangelis Method in Evangelis Method lecture of STT Simpson Students. Evangelism is the Great Commission of our Lord Jesus Christ (Mat. 28:18-20), so that STT Simpson emphasize on the fulfillment of the Great Commission. This study describes the achievements of the implementation of Evangelism practices and what are the factors inhibiting the adoption of Evangelis practices method on students participating in courses Evangelis method even academic year 2014-2015. This method of research used in this research is qualitative research. The data in this study were obtained through focus group discussions, interviews open, and report student practice. The results obtained is 1) The achievement of student practice only reached the stage of submission of the Gospel, 2) Factors difficulty implementing Evangelis practices are internal factors: $55.55 \%$, and external factors: $44.44 \%$.
\end{abstract}

Keyword: Evangelis Method, Evangelis Practic

\begin{abstract}
ABSTRAK: Jamin Tanhidy, Praktik Metode Penginjilan Pada Mata Kuliah Metode Penginjilan Mahasiswa STT Simpson Ungaran. Penginjilan merupakan Amanat Agung Tuhan Yesus Kristus (Mat. 28:1820), sehingga STT Simpson menekankan pada pemenuhan Amanat Agung tersebut. Penelitian ini menguraikan tentang capaian pelaksanaan praktik PI dan apa saja yang menjadi faktor penghambat pelaksanaan praktik Metode PI pada mahasiswa peserta mata kuliah Metode PI semester Genap tahun ajaran 20142015. Jenis penelitian yang digunakan dalam penelitian ini adalah penelitian kualitatif. Data dalam penelitian ini diperoleh melalui FGD, wawancara terbuka, dan laporan praktik mahasiswa. Hasil penelitian yang diperoleh adalah 1) Capaian praktik mahasiswa hanya sampai pada tahap penyampaian Injil, 2) Faktor kesulitan melaksanakan praktik PI adalah faktor internal: 55,55\%, dan faktor eksternal: 44,44\%.
\end{abstract}

Kata kunci: Metode Penginjilan, Praktik Penginjilan

\section{PENDAHULUAN}

Dalam Matius 28:18-20 dituliskan bahwa

Yesus Kristus memberikan amanat kepada muridmurid-Nya. Amanat tersebut merupakan perintah untuk pergi menjadikan semua bangsa murid Kristus dan membaptis setiap orang yang menjadi muridNya dalam nama Bapa, Anak dan Roh Kudus. Kemudian mengajar setiap murid untuk melakukan segala sesuatu yang telah diperintahkan Kristus. Ayat tersebut merupakan Amanat Agung Yesus Kristus untuk melakukan pemuridan dan penginjilan. Istilah ini dipakai oleh penulis Alkitab untuk menjelaskan tentang berita dari Kerajaan Sorga, yaitu Injil Yesus Kristus yakni berita tentang pengampunan dosa yang disediakan Allah bagi semua manusia berdosa melalui iman kepada pengorbanan Anak-Nya, Yesus
Kristus di kayu salib serta kebangkitan-Nya dari antara orang mati, olehnya manusia tidak binasa melainkan mendapatkan hidup yang kekal (Yoh. 3:16; 1 Kor. 15:1-4). Yakob Tomatala menuliskan dalam bukunya bahwa "Injil adalah kuasa Allah yang membawa keselamatan dari Allah (Roma 1:16-17). Injil telah ditetapkan oleh Allah untuk memenuhi rencana keselamatan-Nya yang kekal yang membawa shalom kepada manusia (2 Petrus 3:9). ${ }^{1}$ Sementara Stephen Tong mendefinisikan penginjilan sebagai "proklamasi dinamis tentang Injil penebusan sebagai titik pusat iman kita kepada umat manusia.",

${ }^{1}$ Yakob Tomatala, Teologi Misi (Jakarta: YT Leadership Foundation, 2005), 209.

${ }^{2}$ Stephen Tong, Teologi Penginjilan (Jakarta: LRII, 1988), 2. 
Dalam tulisan ini penginjilan yang dimaksud di sini ialah segala usaha yang dilakukan untuk memberitakan atau memproklamirkan berita tentang pengampunan dosa kepada setiap orang berdosa agar mereka tidak binasa karena dosa-dosa mereka, melainkan diselamatkan dari murka Allah serta mendapatkan hidup yang kekal melalui iman kepada pengorbanan Yesus Kristus di kayu salib dan kebangkitan-Nya dari orang mati (Mrk. 16:15; Rm. 6:23; Kis. 1:8).

Sebagaimana telah diutarakan di awal bahwa penginjilan merupakan Amanat Agung Yesus Kristus, sehingga setiap orang Kristen dituntut untuk memberitakan Injil kepada semua orang. D. James Kennedy dalam bukunya menekankan bahwa dalam memberitakan Injil adalah tugas semua orang percaya, selain para rasul juga pergi dan memberitakan Injil. ${ }^{3}$ Adapun alasan melakukan tugas penginjilan adalah: 1) Kehendak Allah (2 Pet. 3:9b); 2) Takut akan murka Allah (2 Kor. 5:11; 20); 3) Amanat Agung Tuhan Yesus (Mrk. 16:15; Mat. 28:19-20); 4) Membagikan kasih Kristus (2 Kor. 5:14-15); 5) Teladan Rasul-Rasul (Kis. 1:8;28:31); 6) Mengasihi orang berdosa (Yoh. 3:16; 1 Tes. 2:8); 7) Hutang (Rm. 1:14-15); 8) Sukacita dan mahkota (1 Tes. 2: 19-20); 9) Kedatangan Kristus kedua kali/Maranata (Mat. 24:14; 2 Pet. 3:11-12a). ${ }^{4}$

Memperhatikan Amanat Agung tersebut, Sekolah Tinggi Teologi (STT) Simpson dalam visinya menekankan pada upaya melahirkan lulusan yang Injili. Untuk itu STT Simpson memperlengkapi setiap mahasiswa di dua prodinya yaitu Prodi S1 Teologi Kependetaan dan Prodi S1 Pendidikan Agama Kristen (PAK) dengan keterampilan penginjilan. Untuk memperlengkapi mahasiswa dengan keterampilan penginjilan, STT Simpson menyelenggarakan beberapa mata kuliah penginjilan salah satunya adalah mata kuliah Metode Penginjilan (PI). Mata kuliah tersebut diajarkan dengan menekankan

${ }^{3}$ D. James Kennedy, Ledakan Penginjilan (Jakarta: EE Internasional III, t.t.), 10.

${ }^{4}$ Mangapul Sagala, Pekabaran Injil Secara Pribadi (Jakarta: Perkantas, 2002), 4-14. pada pemahaman teori dan keterampilan melakukan PI melalui praktik. Sesuai dengan desain kurikulum STT Simpson, mata kuliah Metode PI diajarkan pada mahasiswa tingkat satu semester genap. Tujuan dari mata kuliah tersebut adalah mahasiswa mampu mempraktikkan metode-metode yang telah diajarkan.

Berdasarkan evaluasi penyelenggaraan mata kuliah Metode PI pada beberapa semester yang telah berjalan oleh dosen pengampu mata kuliah Metode PI, nampak bahwa pada praktik mata kuliah ini mengalami beberapa masalah atau terdapat hambatan-hambatan pada saat melakukan praktik penginjilan. Memang hambatan melakukan praktik Metode PI dapat timbul dari dalam diri mahasiswa yang melakukan penginjilan maupun dari orang-orang yang diinjili. Pelaksanaan praktik dan hambatan-hambatan yang dihadapi, perlu segera diketahui sehingga dapat dilakukan perbaikan pada pelaksanaan praktik selanjutnya. Untuk mengetahui bagaimana pelaksanaan praktik metode PI dan hambatan-hambatan yang dihadapi, maka perlu dilakukan penelitian pada mahasiswa yang melakukan praktik mata kuliah Metode PI semester Genap Tahun Ajaran 20142015.

Pada semester Genap Tahun Ajaran 20142015, mata kuliah Metode PI kembali diselenggarakan dengan peserta 13 orang dari Prodi S1 Teologi Kependetaan dan 12 orang dari Prodi S1 Pendidikan Agama Kristen. Praktik mata kuliah Metode PI pada semester Genap Tahun Ajaran 2014-2015 direncanakan akan dilaksanakan sebanyak 5 kali praktik lapangan. Mahasiswa akan dibagi dalam 5 kelompok yang masing-masing kelompok terdiri dari 5 orang.

Rumusan masalah penelitian ini adalah bagaimana capaian pelaksanaan praktik PI pada mahasiswa peserta mata kuliah Metode PI semester Genap tahun ajaran 2014-2015? Serta apa yang menjadi faktor penghambat pelaksanaan praktik Metode PI pada mahasiswa peserta mata kuliah Metode PI semester Genap tahun ajaran 2014-2015? Adapun tujuan dari penelitian ini adalah 1) Menemukan ca- 
paian pelaksanaan praktik PI pada mahasiswa peserta mata kuliah Metode PI semester Genap tahun ajaran 2014-2015; 2) Menemukan apa saja yang menjadi faktor penghambat pelaksanaan praktik Metode PI pada mahasiswa peserta mata kuliah Metode PI semester Genap tahun ajaran 2014-2015.

\section{METODE}

Jenis penelitian ini dari sisi dominan adalah penelitian deskriptif kualitatif. Penelitian ini menguraikan dari sudut pandang peneliti apa yang terjadi pada praktik Penginjilan pada mahasiswa peserta mata kuliah Metode PI Semester Genap Tahun Ajaran 2014-2015 di STT Simpson. Dinyatakan penelitian deskriptif kualitatif karena dalam penelitian ini diuraikan data-data dalam bentuk deskriptif berupa tulisan dan perilaku orang yang diamati. Proses penelitian ini dilaksanakan dengan mengajukan pertanyaan-pertanyaan, mengumpulkan data dari partisipan, menganalisi data dan menafsirkan data sehingga data yang dihasilkan adalah kata-kata, gambar, dan bukan angka-angka. ${ }^{5}$ Dari sisi cakupan studinya, penelitian ini adalah penelitian studi kasus. Dalam penelitian ini peneliti menyelidiki suatu aktivitas atau proses yang dilakukan oleh sekelompok individu. ${ }^{6}$

Penelitian ini dilakukan di STT Simpson Ungaran, dengan objek penelitiannya adalah pada mahasiswa peserta mata kuliah Metode PI semester Genap tahun ajaran 2014-2015. Penelitian di STT Simpson dilakukan untuk mengumpulkan data-data hasil wawancara maupun Focus Group Discussion (FGD), sementara penelitian di lokasi PI para mahasiswa dilakukan dengan pengamatan atau observasi. Dalam penelitian ini data yang dikumpulkan adalah data primer dan data skunder. Data primer diperoleh melalui FGD dan Wawancara. FGD dilaksanakan

${ }^{5}$ Lexy J. Moleong, Metode Penelitian Kualitatif (Bandung: Remaja Rosdakarya, 2010), 15.

${ }^{6}$ John W. Creswell, Research Design: Pendekatan Kualitatif, Kuantitatif, dan Mixed (Yogyakarta: Pustaka Pelajar, 2013), 20. dengan melibatkan para mahasiswa yang mengikuti Mata Kuliah Metode PI Semester Genap Tahun Ajaran 2014-2015. Sementara teknik wawancara yang digunakan adalah wawancara terbuka berpedoman untuk memperoleh penjelasan pelaksanaan praktik metode PI. Data sekundernya akan diperoleh melalui studi dokumentasi dan observasi. Dalam mengumpulkan data, peneliti melakukan observasi partisipatif dengan terlibat dalam pelaksanaan PI untuk memperoleh gambaran awal dan keadaan pelaksanaan PI mahasiswa. Analisis data yang digunakan dalam penelitian ini adalah analisis data model Miles dan Huberman. Uji kepercayaan dilakukan dalam penelitian ini untuk mengetahui apakah semua data yang diperoleh dari hasil FGD, Wawancara dan Observasi sudah valid dan reliabel.

\section{HASIL}

\section{Capaian Praktik Metode PI}

Berdasarkan hasil FGD dan data laporan praktik PI 25 orang mahasiswa STT Simpson yang mengkuti mata kuliah Metodo PI pada semester Genap 2014-2015 ditemukan capaian praktik metode PI sebagai berikut:

Tabel 1.

Capaian Praktik PI

\begin{tabular}{|l|c|c|c|c|}
\hline \multirow{2}{*}{ Tahapan } & \multicolumn{4}{|c|}{$\begin{array}{c}\text { Prosentase Capaian Pada } \\
\text { Praktik }\end{array}$} \\
\cline { 2 - 5 } & I & II & III & IV \\
\hline Perkenalan & $60 \%$ & $40 \%$ & $32 \%$ & $32 \%$ \\
\hline Injil & & & & \\
A. Anugerah & $20 \%$ & $28 \%$ & $20 \%$ & $32 \%$ \\
B. Allah & -- & $20 \%$ & $20 \%$ & $8 \%$ \\
C. Kristus & $12 \%$ & $8 \%$ & $8 \%$ & $12 \%$ \\
D. Iman & $8 \%$ & $4 \%$ & $12 \%$ & $16 \%$ \\
\hline
\end{tabular}

Pada tahap penyerahan diri hingga tindak lanjut langsung, berdasarkan hasil FGD ditemukan bahwa belum ada mahasiswa yang mencapai tahap tersebut. Tahap yang belum dicapai dari empat kali praktik 
adalah (1) Penyerahan diri yang meliputi: pertanyaan pengujian, pertanyaan penyerahan diri, penjelasan penyerahan diri, doa untuk penyerahan diri, jaminan keselamatan; (2) Tindak lanjut langsung diantaranya: ucapan selamat datang, pembicaraan tentang partner dalam bertumbuh, sarana pertumbuhan, dan janji untuk ke gereja.

Faktor yang menjadi penyebab tidak tercapainya dua tahapan tersebut karena dua tahap tersebut bengantung pada penyelesaian tahap sebelumnya. Dari data yang diperoleh, dua tahap tersebut belum tercapai karena semua pembicaraan dalam praktik antara mahasiswa dengan orang yang dilayani terhenti pada tahap pembicaraan tentang Injil. Pada praktik I hanya $8 \%$ mahasiswa yang dapat menyelesaikan pembicaraan tentang Iman, lalu pada praktik II ada $4 \%$, yang menyelesaikan pembicaraan tentang Iman, pada praktik III hanya $12 \%$ yang menyelesaikan pembicaraan tentang Iman, dan pada praktik IV hanya $16 \%$ mahasiswa yang dapat menyelesaikan pembicaraan tentang Iman. Dengan demikian tahap berikutnya tidak dilaksanakan dalam praktik.

\section{Faktor Kesulitan Praktik PI}

Melihat data yang diperoleh terkait dengan capain praktik PI 25 orang mahasiswa STT Simpson yang mengikuti mata kuliah Metodo PI, penulis kemudian melakukan penelitian terhadap faktor-faktor penyebab kesulitan melakukan praktik. Hasil yang diperoleh melalui FGD, wawancara pribadi, dan laporan praktik mahasiswa maka ditemukan hasil sebagai berikut:

Tabel 2.

Prosentase Faktor Kesulitan Praktik PI

\begin{tabular}{|l|c|}
\hline \multicolumn{1}{|c|}{ Faktor } & Prosentase \\
\hline Faktor Internal & $55,55 \%$ \\
\hline Faktor Eksternal & $44,44 \%$ \\
\hline
\end{tabular}

Penulis mengelompokkan faktor-faktor kesulitan yang ditemukan dalam penelitian sebagai berikut:

\section{Faktor Internal}

Pada faktor internal terdapat beberapa kesulitan yang dihadapi yaitu (1) Penyampaian masih kaku. Hal ini disebabkan minimnya penguasaan materi praktik; (2) Rasa takut untuk masuk pada beberapa bagian pada tahap penyampaian Injil. Rasa takut timbul karena minimnya persiapan dan pengalaman praktik; (3) Rasa malas pada mahasiswa untuk pergi dan melakukan praktik. Hal ini sangat berkaitan dengan sikap dan kemauan mahasiswa untuk melaksanakan praktik; (4) Kesulitan untuk menguasai metode sehingga lupa pada tahap atau bagian-bagian tertentu. Panjang metode dan dibutuhkan waktu panjang untuk menghafal serta memahami metode yang digunakan menjadi penyebabnya; (5) Mahasiswa merasa waktu yang dibutuhkan terlalu panjang sehingga orang yang dilayani kurang dapat memperhatikan dengan baik; (6) Kurangnya simulasi di kelas.

\section{Eksternal}

Pada faktor eksternal, ada beberapa faktor kesulitan yang dihadapi, yaitu (1) Orang yang dilayani mengakhiri pembicaran dan meninggalkan mahasiswa. Dalam sesi FGD, diungkapkan bahwa lawan bicara mengakhiri pembicaran tanpa alasan yang jelas; (2) Metode yang digunakan terlalu panjang sehingga membuat orang yang dilayani atau diajak bicara merasa jenuh. Masalah ini ditemui oleh mahasiswa dengan inisial Arb., JC., Mh., DT, dan Rt.; (3) Orang yang dilayani merasa waktu mereka terlalu banyak tersita dalam pembicaraan. Hal ini berkaitan dengan panjangnya pembicaraan untuk menyampaikan Injil; dan (4) Dalam beberapa praktik, pembicaraan diganggu oleh orang lain.

\section{PEMBAHASAN}

Mencermati hasil penelitian yang diperoleh dan analisa yang dilakukan, penulis menilai minimnya simulasi praktik mempengaruhi pelaksanaan praktik. Hasil FGD yang dihimpun penulis terkait hal ini, dapat disimpulkan bahwa mahasiswa merasa membutuhkan simulasi utuh yang lebih banyak dan 
diskusi paska praktik. Simulasi yang dilaksanakan di kelas mata kuliah metode PI ternyata hanya dilaksanakan dua kali dan melibatkan empat orang mahasiswa. Dalam sesi FGD, peserta kelas mengemukakan pendapat bahwa mereka perlu memperoleh jumlah simulasi yang lebih banyak dan masing-masing mahasiswa perlu memperoleh kesempatan untuk mengikuti simulasi. Semulasi yang dilaksanakan di dalam kelas dengan intensitas yang cukup banyak memang akan menambah pengalaman dan pemahaman mahasiswa dalam melaksanakan praktik. Dapat dipahami bahwa sulitnya mencapai hasil yang maksimal dalam melaksanakan praktik disebabkan karena masih perlu ditambahnya jumlah simulasi.

Sementara paska praktik langsung, mahasiswa merasa perlu ada evaluasi dan diskusi untuk memecahkan masalah yang dihadapi. Mereka merasa perlu ada evaluasi dan diskusi yang dapat memberikan jalan keluar dalam menghadapi kesulitan praktik PI. Diskusi juga diperlukan untuk dapat mengembangkan metode yang digunakan sesuai dengan konteksnya. Meski penelitian ini bukan merupakan penelitian tindakan, dalam sesi FGD III, penulis mencoba memberi kesempatan mendiskusikan kesulitan dalam praktik dan bagaimana menyelesaikan masalah yang dihadapi. Ternyata dalam sesi FGD IV, peserta kelas mengemukakan bahwa hasil diskusi dalam FGD III bermanfaat bagi mereka dalam melaksanakan praktik penginjilan. Dari hal tersebut, penulis menilai bahwa dalam praktik mata kuliah Metode PI perlu disusun jadwal atau sesi untuk diskusi, sehingga masing-masing kesulitan yang dihadapi oleh peserta kelas dapat dipecahkan bersama dan dapat saling memperkaya pengetahuan peserta kelas.

Evaluasi paska praktik langsung atau praktik lapangan dapat menjadi sesi diskusi untuk mengetahui kendala-kendala yang dihadapi dalam pelaksa-

\section{DAFTAR RUJUKAN}

Creswell, John W. Research Design: Pendekatan Kualitatif, Kuantitatif, dan Mixed. Yogyakarta: Pustaka Pelajar, 2013. naan praktik lapangan. Selain itu, evaluasi diperlukan agar hal-hal praktis yang ditemukan dalam praktik lapangan dapat dibagikan dalam sesi diskusi.

\section{KESIMPULAN}

Dari hasil penelitian ini diketahui bahwa capaian praktik PI mahasiswa yang meningkuti mata kuliah Metode PI pada semester Genap tahun ajaran 2014-2015 hanya mencapai tahap penyampaian Injil. Sementara tahap yang belum dicapai dari empat kali praktik adalah (1) Penyerahan diri yang meliputi: pertanyaan pengujian, pertanyaan penyerahan diri, penjelasan penyerahan diri, doa untuk penyerahan diri, jaminan keselamatan; (2) Tindak lanjut langsung diantaranya: ucapan selamat datang, pembicaraan tentang partner dalam bertumbuh, sarana pertumbuhan, dan janji untuk ke gereja. Faktor yang menjadi penyebab tidak tercapainya dua tahapan tersebut karena dua tahap tersebut bengantung pada penyelesaian tahap sebelumnya. Faktor kesulitan praktik PI yang ditemukan adalah (1) faktor internal: penyampaian masih kaku, rasa takut untuk masuk pada beberapa bagian pada tahap penyampaian Injil, rasa malas pada diri mahasiswa untuk dan melakukan praktik, kesulitan untuk menguasai metode sehingga lupa pada tahap atau bagian-bagian tertentu, mahasiswa merasa waktu yang dibutuhkan terlalu panjang sehingga orang yang dilayani kurang dapat memperhatikan dengan baik, dan kurangnya simulasi di kelas; 2) faktor eksternal adalah orang yang dilayani mengakhiri pembicaran dan meninggalkan mahasiswa, metode yang digunakan terlalu panjang sehingga membuat orang yang dilayani merasa jenuh, orang yang dilayani merasa waktu mereka terlalu banyak tersita dalam pembicaraan, pembicaraan diganggu oleh orang lain.

Kennedy, D. James. Ledakan Penginjilan. Jakarta: EE Internasional III, t.t. 
Moleong, Lexy J. Metode Penelitian Kualitatif. Tomatala, Yakob. Teologi Misi. Jakarta: YT LeaBandung: Remaja Rosdakarya, 2010. dership Foundation, 2005.

Sagala, Mangapul. Pekabaran Injil Secara Pribadi. Tong, Stephen. Teologi Penginjilan. Jakarta: LRII, Jakarta: Perkantas, 2002. 1988. 